\title{
Pathological analysis on transurethral enucleation resection of the prostate-related prostate surgical capsule
}

\author{
Shiping Wei ${ }^{1,2}$, Fan Cheng ${ }^{1}$, Weiming $\mathrm{Yu}^{1}$ \\ ${ }^{1}$ Department of Urology, Wuhan University Renmin Hospital, Wuhan, China \\ ${ }^{2}$ Department of Urology, General Hospital of The Yangtze River Shipping, Wuhan, China
}

\begin{abstract}
Introduction: Transurethral enucleation resection of the prostate (TUERP) is one of the most important minimally invasive methods for the treatment of benign prostatic hyperplasia $(B P H)$. There have been many reports on the therapeutic effects of TUERP. However, reports on prostate surgical capsule recognition and pathological analysis are rare. Aim: To compare the pathological features of the prostate surgical capsule between TUERP and suprapubic open prostatectomy (SOP).

Material and methods: Eighty samples were collected; samples 1-3 were prostate gland tissue, tissue adjacent to the prostate surgical capsule, and prostate surgical capsule tissue, respectively. HE staining was used to analyze the pathological components; the enucleation rate was compared between both groups.

Results: The pathological features of the prostate surgical capsule for both groups were roughly the same: sample 1 was mostly gland, with lesser amounts of smooth muscle and fibrous tissue components; sample 2 was mostly fibrous tissue and a smooth muscle component and a small amount of glandular components, and, closer to the surgical capsule, more fibrous tissue, less glandular component; sample 3 was mainly fibrous tissue, and almost no glandular component; there were the same differences among samples $1-3$ in both groups $(p<0.05)$. The enucleation rate for TUERP and SOP was roughly the same, about $58.2 \%$, and there was no significant difference ( $p>0.05)$. Conclusions: The prostate surgical capsule in TUERP was similar to SOP, which consisted mainly of smooth muscle and fibrous tissue. Moreover, SOP combined with transurethral resection of the prostate (TURP) can treat BPH for a large volume of prostate (> $100 \mathrm{ml})$, but its effectiveness and safety need further large-scale clinical trials for confirmation.
\end{abstract}

Key words: enucleation, surgical capsule, prostate, open, transurethral.

\section{Introduction}

Benign prostatic hyperplasia (BPH) is a common disease in elderly men. In recent years owing to growing number of elderly people, the incidence rate has clearly increased year by year [1]. Surgical treatment of BPH in recent decades has been performed by suprapubic open prostatectomy (SOP), transurethral resection of the prostate (TURP), and transurethral enucleation resection of the prostate
(TUERP). Although the surgical method was constantly improving, the scope of surgical resection was based on achieving the prostate surgical capsule, but the recognition of the prostate surgical capsule required excellent practical experience, owing to capsule identification being unclear, leading to perforation of the capsule, causing surgical injury, and even leading not uncommonly to serious complications of the situation, so the study of the prostate surgical capsule has important clinical sig-

\section{Address for correspondence}

Dr. Fan Cheng, Department of Urology, Wuhan University, Renming Hospital, 238 Jiefang Road, 430060 Wuhan, China,

e-mail:wgy820578@126.com 
nificance [2-6]. This study was designed to compare the similarities and differences in the pathology of the prostate surgical capsule between TUERP and SOP, while introducing SOP combined with salvaged TURP for the treatment of a large volume of BPH.

\section{Aim}

The aim of the study was to compare the pathological features of the prostate surgical capsule between TUERP and SOP.

\section{Material and methods}

\section{Study participants}

From January 2014 to February 2017, 80 BPH patients were enrolled and were divided into the TUERP group ( $n=40$ patients) and the SOP group (control group, $n=40$ patients). All patients underwent preoperative prostate-specific antigen (PSA), digital rectal examination (DRE), post-void residual volume (PVR), International Prostate Symptom Score (IPSS), quality of life $(\mathrm{QOL})$ and maximum flow rate of urine (Qmax). Prostate weight and volume were examined and calculated (volume $=$ upper and lower diameter $\times$ antero posterior diameter $\times$ left and right diameter $\times 0.52$, weight $=$ volume $\times 1.05$ ). Patients' exclusion criteria: 1) prostate volume is too small, less than $40 \mathrm{~g}$; 2) patients with significant coagulation dysfunction; 3) patients with significant cardiopulmonary insufficiency cannot tolerate surgery; 4) body deformity cannot tolerate supine position; 5) other combined medical diseases affecting anesthesia or surgery.

\section{TUERP surgical procedures}

All surgical procedures were completed by a senior medical chief physician, the patients have been taking the lithotomy position after anesthesia, disinfection was completed, adjusted power level of the resectoscope to $160 \mathrm{~W}$, electrocoagulation power to $100 \mathrm{~W}$, observed the urethra prostate and bladder clearly, the TUERP included four steps: The first step: at 10-2 o'clock direction we cut the gland to the prostate surgical capsule to facilitate the formation of enucletation marker and drainage channel; The second step: at the fine level we cut to the capsule layer of the left side and enucleated retrogradely the prostate gland, retaining at 5 o'clock part of the bladder neck in order to prevent the gland moving into the bladder, in the same way enucleated the right side of the prostate glandular tissue, and retained the glandular tissue at 7 o'clock of the bladder neck. The third step: the prostate tissue was cut rapidly between the gland and the urethra, or between the gland and the capsule. The fourth step: we dressed the prostate tip, bladder neck, and checked for potential bleeding points and gave hemostasis carefully, and retained the catheter, then the surgery was over.

\section{SOP surgical procedures}

All the surgical procedures were completed by a senior medical chief physician. The patients adoped the supine position after anesthesia. Disinfection was completed, an incision was made at the middle of the abdomen, we cut the skin layer by layer, subcutaneous tissue, muscle, opened the bladder, and cut the bladder neck. We enucleated the bilateral prostate gland by finger, then sutured the bladder neck and hemostasis and formed the bladder neck outlet (accommodated one index finger), and sutured the bladder after retaining the bladder drainge tube, transurethral endoscopy into the prostate and observed the prostate surgical capsule. Active bleeding was given coagulation hemostasis, and we dressed the wound surface of the prostate surgical capsule appropriately.

\section{Samples required and staining method}

All samples 1-3 were required from prostate glandular tissue, tissue adjacent to the prostate surgical capsule, and prostate surgical capsule tissue, respectively; all samples were subjected to HE staining. In addition, we compared the enucleation rate for both groups.

\section{Statistical analysis}

SPSS 16.0 statistical software was adopted, measurement data were expressed as mean \pm standard deviation; the $\chi^{2}$ test was used for the enucleation rate of intragroup comparisons, the paired t-test was used for baseline of intragroup comparisons, single-factor analysis of variance was used for the three groups, $p<0.05$ was statistically significant.

\section{Results}

Firstly, the basic information of both groups is presented in Table I. There were no differences among AGE, PSA, PVR, IPSS, QOL, Qmax $(p>0.05)$ (See Table I for details). 
Table I. Comparison of general data between groups

\begin{tabular}{|lccc|}
\hline Parameter & TUERP $(n=40)$ & SOP $(n=40)$ & $P$-value \\
\hline Age [years] & $72.3 \pm 5.2$ & $72.6 \pm 6.5$ & 0.069 \\
\hline Prostate volume [ml] & $68.5 \pm 7.5$ & $120.4 \pm 5.3$ & 0.021 \\
\hline IPSS & $16.8 \pm 4.3$ & $15.1 \pm 3.6$ & 0.087 \\
\hline QOL & $3.8 \pm 0.5$ & $3.7 \pm 0.5$ & 0.067 \\
\hline PSA [ng/ml] & $5.2 \pm 0.5$ & $6.2 \pm 1.1$ & 0.091 \\
\hline Qmax. [ml/s] & $10.4 \pm 3.1$ & $10.2 \pm 4.3$ & 0.097 \\
\hline PVR $[\mathrm{ml}]$ & $80.2 \pm 15.4$ & $81.6 \pm 13.7$ & 0.078 \\
\hline
\end{tabular}

\section{TUERP group}

In samples 1,33 of 40 cases were glandular tissue, 5 cases were glandular tissue mixed with a small amount of muscle fibers, 2 case were gland tissue mixed with a small amount of inflammatory cells; in samples 2, 26 of 40 cases were muscle fiber-based, with a small amount of inflammatory cells, 10 cases were glandular tissue mixed with a small amount of muscle fiber tissue, 4 cases were glandular tissue mixed with a small amount of fibrous tissue; in samples 3, 38 of 40 cases were fibrous tissue, 2 cases were fibrous tissue mixed with a small amount of inflammatory cells; obviously, samples 1 were gland mostly; samples 2 were fibrous tissue and smooth muscle component mostly, and more close to the prostate surgical capsule, more fibrous tissue, less glandular component; samples 3 mainly were fibrous tissue and almost no glandular component; there were differences among samples $1-3(p<0.05)$ (Table II and Photos 1, 2).

\section{SOP group}

In samples 1, 34 of 40 cases were glandular tissue, 4 cases were muscle fibers mixed with a small amount of glandular tissue, 2 cases were fibrous and mixed with a small amount of inflammatory cells; in samples 2, 27 of 40 cases were muscle fibrous tissue mixed with a small amount of inflammatory cells, 9 cases were glandular tissue mixed with a small amount of muscle fiber tissue, 4 cases were fibrous tissue mixed with a small amount of glandular tissue; in samples 3, 37 of 40 cases were fibrous tissue, 3 cases were smooth muscle tissue mixed with a small amount of inflammatory cells. With the same results as the TUERP group above mentioned, we found there were the same differences among samples $1-3$ in the SOP group $(p<0.05)$ (Table II and Photos 1, 2).

Finally, the enucleation rate for TUERP group was $58.2 \%$, and $58.3 \%$ for the SOP group. The results show that both groups of resected prostate tissue were relatively close; there was no significant difference $(p>0.05)$. Moreover, the prostate surgical capsule after the removal of prostate tissue in both groups was also similar to the naked eye (Table III and Photo 3).

\section{Discussion}

According to McNeal, on partition of the prostate, $\mathrm{BPH}$ often originated in the gland around the

Table II. Comparison of HE findings between groups

\begin{tabular}{|c|c|c|c|c|c|c|c|c|c|c|}
\hline \multirow[t]{2}{*}{ Parameter } & \multicolumn{3}{|c|}{ Sample $1(n=40)$} & \multicolumn{3}{|c|}{ Sample $2(n=40)$} & \multicolumn{3}{|c|}{ Sample $3(n=40)$} & \multirow[t]{2}{*}{$P$-value } \\
\hline & $\begin{array}{l}\text { Glandular } \\
\text { tissue }\end{array}$ & $\begin{array}{l}\text { Smooth } \\
\text { muscle }\end{array}$ & $\begin{array}{l}\text { Fibrous } \\
\text { tissue }\end{array}$ & $\begin{array}{l}\text { Glandular } \\
\text { tissue }\end{array}$ & $\begin{array}{l}\text { Smooth } \\
\text { muscle }\end{array}$ & $\begin{array}{l}\text { Fibrous } \\
\text { tissue }\end{array}$ & $\begin{array}{l}\text { Glandular } \\
\text { tissue }\end{array}$ & $\begin{array}{l}\text { Smooth } \\
\text { muscle }\end{array}$ & $\begin{array}{l}\text { Fibrous } \\
\text { tissue }\end{array}$ & \\
\hline TUERP & 33 & 5 & 2 & 10 & 26 & 4 & 0 & 2 & 38 & 0.013 \\
\hline SOP & 34 & 4 & 2 & 9 & 27 & 4 & 0 & 3 & 37 & 0.024 \\
\hline$P$-value & 0.065 & 0.067 & 0.121 & 0.087 & 0.091 & 0.121 & 0.213 & 0.067 & 0.069 & 0.035 \\
\hline
\end{tabular}



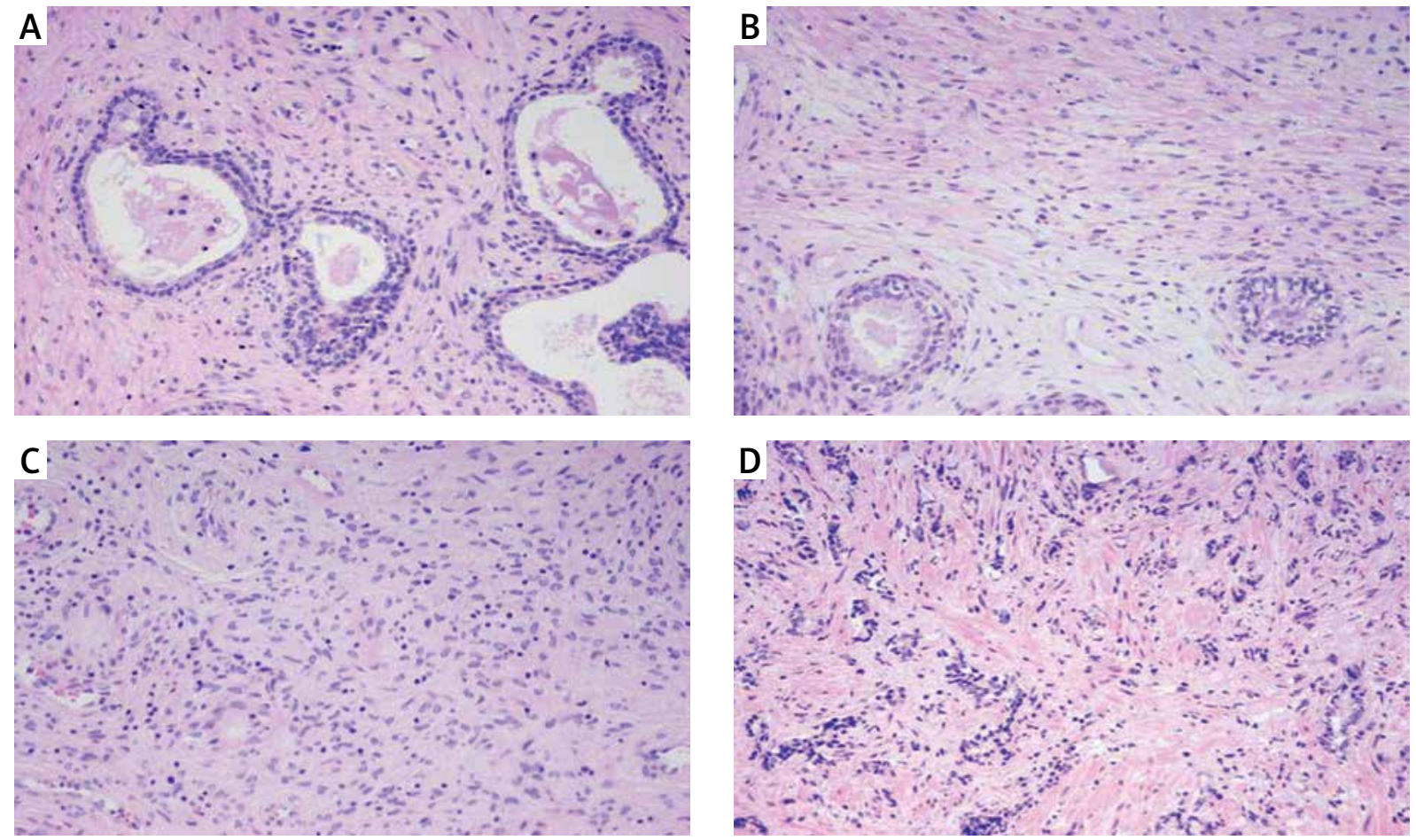

Photo 1. SOP group specimens 1-3 H + E staining picture 200×: A - mainly glandular hyperplasia, a small amount of smooth muscle; B - smooth muscle-based, a small amount of glandular hyperplasia; C, D - fibrous tissue, smooth muscle hyperplasia, almost no glands
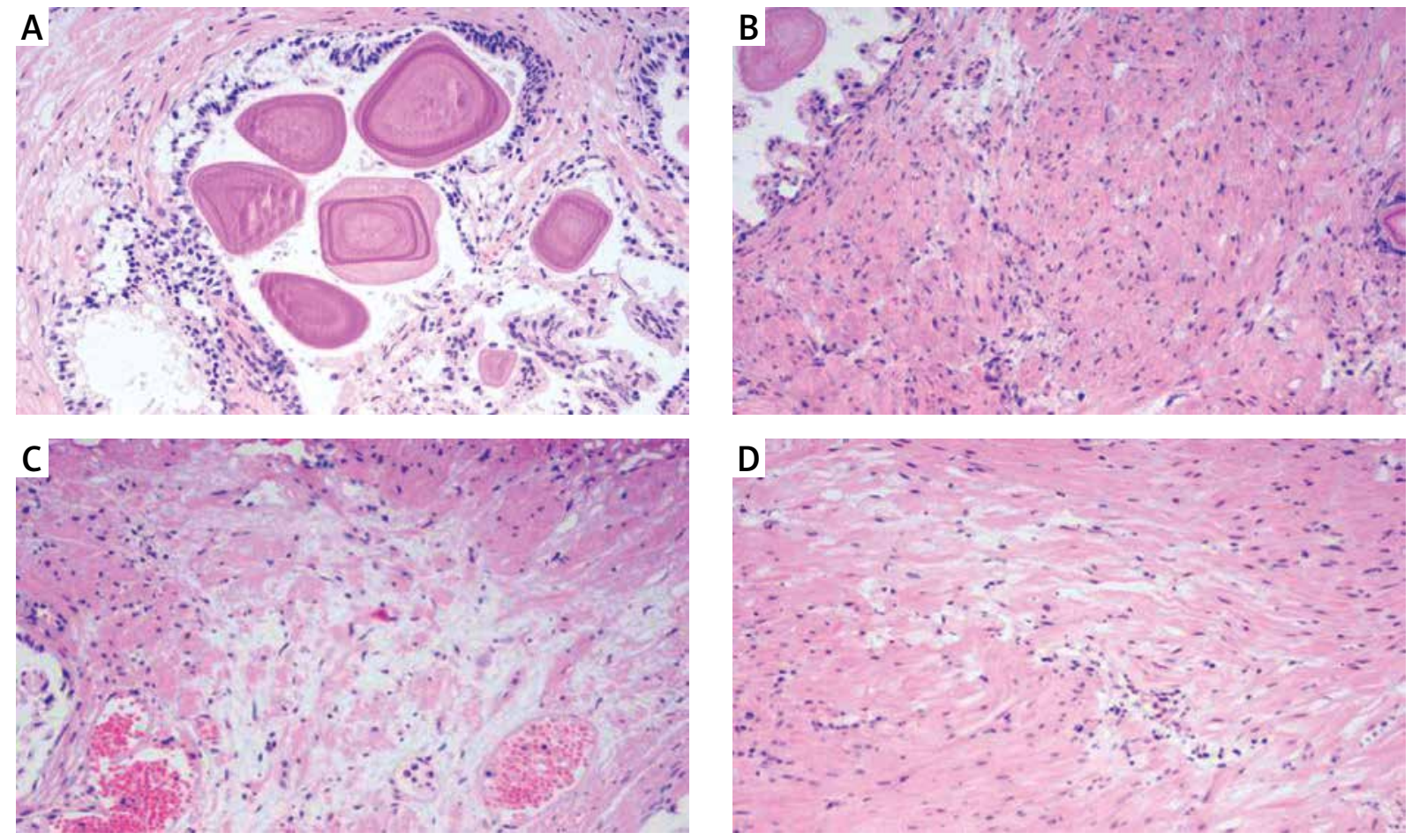

Photo 2. TUERP group of specimens 1-3 H + E staining picture 200x: A - mainly glandular hyperplasia, a small amount of smooth muscle; B - smooth muscle-based, a small amount of glandular hyperplasia; C, D - fibrous tissue, smooth muscle hyperplasia, almost no glands 
Table III. Comparison of enucleation results between groups

\begin{tabular}{|lccc|}
\hline Parameter & Preoperative prostate weight $[\mathrm{g}]$ & Resection of prostate weight $[\mathrm{g}]$ & Enucleation rate $(\%)$ \\
\hline TUERP & $68 \pm 5.5$ & $39 \pm 5.2$ & 58.2 \\
\hline SOP & $120 \pm 6.8$ & $70 \pm 6.6$ & 58.3 \\
\hline$P$-value & & & 0.097 \\
\hline
\end{tabular}
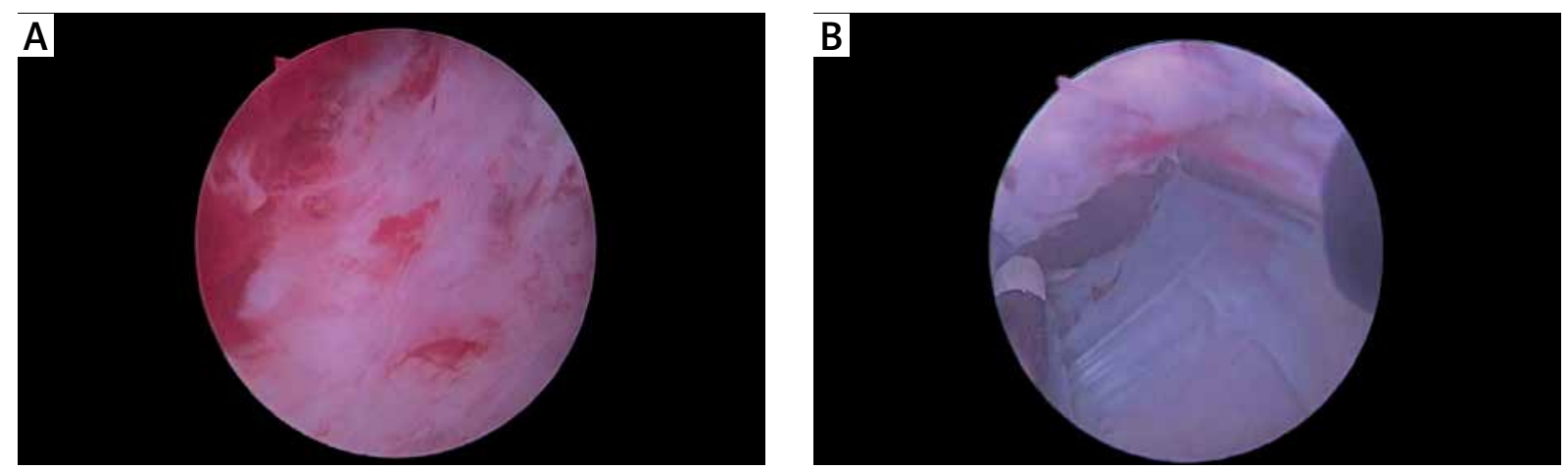

Photo 3. Comparison of two groups of enucleation capsule of prostate surgery: A - SOP group capsule surface; $\mathbf{B}$ - TUERP group capsule surface

urethra and prostate transition zone. The prostate surgical capsule was formed by proliferating prostate nodules compressing the surrounding prostate gland tissue [7]. Prostate surgical capsule thickness ranged from 2 to $5 \mathrm{~mm}$. The enucleation operation was performed between the surgical capsule and the rear compressed gland [7, 8]. Many authors have described the surgical boundary of the "surgical capsule" as "white cross-shaped fiber" or "crude fiber staggered structure" or "coarse mesh weave" structure, but a few authors stated that the microscopic surgical capsule and anatomical capsule cannot be distinguished from each other, believing that cutting to see the coarse fiber bundle or network structure indicated that the prostate surgical capsule has been cut through, and the distance from the prostate urethral to the prostate surgical capsule cannot be measured intraoperatively. Some studies have suggested that the depth of prostate resection should be cut to the prostate capsule and some studies have suggested that prostate resection only need to be cut to the prostate surgical capsule, so this reflected the difference in the depth of cut by the urologist [9-12].

Others have studied how to identify the prostate surgical capsule as the boundary of surgery in TURP correctly. The depth from the prostate surgical capsule to the prostate capsule in TURP was measured by the resectoscope ring, found in different parts of the prostate. There was different thickness between the prostate capsule and the surgical capsule, and it was concluded that in TURP the prostate surgical capsule can be seen as a safe boundary, while the prostate capsule cannot be seen as a safe boundary [13]. Liu et al. thought TUERP was able to resect the glandular tissues similar to SOP, and thought the surgery had several advantages such as quick removal and less bleeding [14], but the study only carried out the longitudinal comparison of samples, and did not study the horizontal comparison of the difference of the prostate surgical capsule between TUERP and SOP. Our results showed that in TUERP and SOP groups, the main components of samples 3 were fibrous tissue, and samples 1 were glandular tissue, and the junction of the two samples were the two mixed ingredients - the closer to the prostate surgical capsule, the more fibrous tissue components and the less glandular tissue (Photos 1 and 2). The results of horizontal comparison between the groups were similar, and there was a significant difference between the groups. It can be concluded that the prostate surgical capsule surface of TUERP was similar to SOP, which was the traditional understanding of enucleation on the prostate surgical capsule, TUERP can perform maximum removal of the prostate tissue on the basis of safety. 
Panalniappan, who compared early postoperative PSA and the Qmax in TURP and TUERP, found that indicators mentioned above in TUERP recovered more ideally, compared to TURP, TUERP cut tissue more thoroughly, and the treatment effect was better [15]. What is more, Limaoyin et al. compared the enucleation rate among TURP, TUERP and SOP, and found the highest enucleation rate for SOP, reaching $39 \%$ [16]. In addition, Tomasz et al. found that the postoperative residual gland accounted for about $36 \%$ of the preoperative prostate volume using the imaging examination for TUERP and SOP [17]. Our study indicated that the enucleation rate for both groups was $58.2 \%$, which was differences with results above mentioned (Table III). It may be related to the following reasons: a difference existed in preoperative prostate volume assessment, because the calculation of preoperative prostate volume included color Doppler ultrasound, MRI and prostate referral examination, which may have resulted in the difference. Furthermore, the surgeon may not be the same person, the prostate tissue removed during the operation was inadvertently lost, and the excised tissue was not weighed after drying, which will have an indirect and direct impact on the results.

Recently, the minimally invasive treatment of $\mathrm{BPH}$ has been constantly innovating. Qiu et al. proposed a non-surgical minimally invasive method - superselective prostatic artery embolization (PAE) for treatment of $\mathrm{BPH}$, which was considered to be suitable for patients with BPH who cannot be operated on or refused surgery, but its long-term efficacy remained to be confirmed [18]. Shin et al. used SOP combined with TURP in large volume BPH patients, and found that postoperative urinary function was significantly improved compared with preoperative values. They believed that this method can significantly reduce the operation time and bleeding, and it was another safe and effective method for treating patients with massive $\mathrm{BPH}$ [19]. In this study, in 40 patients who underwent salvaged TURP after SOP, an intraoperative endoscopic can once again observe the surface of the prostate surgical capsule, and the prostate surgical capsule in TUERP was very similar to the naked eye (Photo 3); meanwhile we can coagulate the prostate surgical capsule surface and resect the residual surgical tissue, to achieve complete hemostasis and prevent glandular tissue loss. In this study, in 1 of the 40 patients it was found that the bladder neck suture was too small, we resected it again under TURP, in a greater degree, which can prevent postoperative urethral stricture, which was a common open surgery complication. One of the 40 patients with significant bleeding in the bladder neck and prostate tip was given appropriate coagulation hemostasis to achieve a real "remedy" effect. In addition, due to the need to pull the catheter for a long time after SOP to prevent bleeding, however, due to prolonged traction and compression it led to urethral sphincter ischemic injury, then postoperative urinary incontinence and postoperative genitourinary infection was greatly increased, so SOP combined TURP in this study can play a role to minimize the risk.

Of course, our research also had certain defects: on the one hand, our sample size was small and it was a single-center study. On the other hand, we did not study the correlation between these pathological structural differences and changes in clinically relevant functions. In view of this, future research projects should avoid using a similarly small sample size, and a multi-centre study should be conducted.

\section{Conclusions}

The prostate surgical capsule consisted mainly of smooth muscle and fibrous tissue, TUERP was similar to SOP, and can effectively remove the glandular tissue in the safe range. SOP combined with TURP may be used as a method for a large volume of BPH (> $100 \mathrm{ml}$ ), but its effectiveness and safety need a large sample of clinical studies for confirmation.

\section{Acknowledgments}

This study was supported by Wuhan Health and Family Planning Commission scientific research project (grant number: WX17Q40).

\section{Conflict of interest}

The authors declare no conflict of interest.

\section{References}

1. Kallenberg F, Hossack TA, Woo HH. Long-term follow-up after electrocautery transurethral resection of the prostate for benign prostatic hyperplasia. Adv Urol 2011; 22: 359-478.

2. Brierly RD, Mostafid AH, Kontothanassis D, et al. Is transurethral resection of the prostate safe and effective in the over 80-year-old? Ann R Coll Surg Engl 2001; 83: 50-3.

3. Marien T, Kadihasanoglu M, Miller NL. Holmium laser enucleation of the prostate: patient selection and perspectives. Res Rep Urol 2016; 8: 181-92. 
4. Jones P, Alzweri L, Rai BP, et al. Holmium laser enucleation versus simple prostatectomy for treating large prostates: results of a systematic review and meta-analysis. Arab J Urol 2016; 14: 50-8.

5. Kim M, Lee HE, Oh SJ. Technical aspects of holmium laser enucleation of the prostate for benign prostatic hyperplasia. Korean J Urol 2013; 54: 570-9.

6. Liu Z, Li D, Chen Y. Endoscopic extraperitoneal radical prostatectomy after radical resection of pT1-pT2 rectalcancer: a report of thirty cases. Videosurgery Miniinv 2017; 12: 68-74.

7. Lowsley OS, Kirwin TJ. Clinical Urology. Williams and Wilkins Press, Baltimore, USA 1956.

8. Epstein Jl. Pathologic assessment of the surgical specimen. Urol Clin North Am 2001; 28: 567-94.

9. Winsbury-White HP. Text Book of Genito-Urinary Surgery. Livingstone Press, Edinburgh, London 1961.

10. Semple JE. Surgical capsule of the benign enlargement of the prostate. Br Med J 1963; 7: 1640-3.

11. Udeh FN. Structure and architecture of the prostatic capsule. Int Urol Nephrol 1982; 14: 35-43.

12. Page $\mathrm{BH}$. The pathological anatomy of digital enucleation for benign prostatic hyperplasia and its application to endoscopic resection. Br J Urol 1980; 52: 111-26.

13. MC Gregor AL. A Synopsis of Surgical Anatomy. William and Wilkins Press, Aurora, USA 1957.

14. Liu C, Zheng S, Li H, et al. transurethral enucleation and resection of prostate in patients with benign prostatic hyperplasia by plasma kinetics. J Urol 2010; 184: 2440-5.

15. Palaniappan S, Kuo TL, Cheng CW, et al. Early outcome of transurethral enucleation and resection of the prostate versus transurethral resection of the prostate. Singapore Med J 2016; 57: 676-80.

16. Li M, Qiu J, Hou Q, et al. endoscopic enucleation versus open prostatectomy for treating large benign prostatic hyperplasia: a meta analysis of randomized controlled trials. Plos One 2015; 10: e0121265.

17. Ishidoya S, Endoh M, Nakagawa H, et al. Novel anatomical finds of the prostatic gland and the surrounding capsular structures in the normal prostate. Tohoku J Exp Med 2007; 212: 55-62.

18. Qiu Z, Zhang C, Wang X, et al. Clinical evaluation of embolization of the superior vesical prostatic artery for treatment of benign prostatic hyperplasia: a single-center retrospective study. Videosurgery Miniinv 2017; 12: 409-16.

19. Shin YS, Zhang LT, Zhao C, et al. Is an adjustment by transurethral surgery simultaneous needed during the suprapubic open prostatectomy? Prostate Int 2015; 3: 31-4.

Received: 14.05.2018, accepted: 10.08.2018. 